\title{
UN NUEVO ENFOQUE PARA EL CÁlCULO DE COLUMNAS CONFINADAS DE HORMIGÓN DE ALTA RESISTENCIA UTILIZANDO EL MÉTODO GENERAL
}

\section{Francisco Aguirre Torrico}

\section{RESUMEN}

Con el creciente aumento del uso de hormigones de alta resistencia (HAR) en las edificaciones y otras obras civiles, es necesario considerar en el cálculo de los elementos estructurales, modelos matemáticos más realistas. En este trabajo se analizó columnas esbeltas sujetas a flexión compuesta, empleando algoritmos que consideran la no linealidad geométrica y física. La no linealidad geométrica está asociada a la curvatura provocada por efectos de segunda orden. La no linealidad física se considera en base al diagrama esfuerzo normal-momento-curvatura, obtenido a partir de las condiciones de equilibrio, compatibilidad de deformaciones y relaciones constitutivas aplicadas al procedimiento del Método General. El Método General, propuesto por el CEB/FIP [1], es lo más exacto para estudiar una estructura de hormigón armado y verifica que pueda existir ruptura del material o inestabilidad del elemento. En este trabajo se han elaborado gráficas de dimensionamiento de esfuerzo axial-momento para columnas de HAR para diversas esbelteces con curvatura simple y simétrica, que fueron ajustadas al dimensionamiento de columnas con curvatura simple o reversa. Con el uso de estas gráficas, el Método General deja de ser un método de verificación y se convierte en un método de dimensionamiento. Debido a la inherente fragilidad del HAR, en las propiedades de los materiales se incluyó el efecto del confinamiento producido por la armadura transversal. Para la obtención de la resultante del hormigón comprimido fue realizada la integración numérica de diagramas tensióndeformación específica más realistas. Los resultados mostraron que considerando el confinamiento se obtiene mayor economía en los materiales, especialmente en columnas sin esbeltez.

Palabras Clave: Columnas, Hormigón de Alta Resistencia, Método General, Confinamiento, Curvas de Dimensionamiento. 